\title{
Dampak Model Bermain Peran Terhadap Hasill Belajar PPKn Siswa Kelas V Sekolah Dasar
}

\author{
Desi Fitriani ${ }^{1 *}$, Nurafni ${ }^{2}$ iD \\ 1,2 Pendidikan Guru Sekolah Dasar, Universitas Muhammadiyah Prof. DR. HAMKA, Jakarta, Indonesia
}

*Corresponding author: desif3700@gmail.com

\begin{abstract}
Abstrak
Penelitian ini bertujuan untuk menganalisis pengaruh hasil belajar dengan menggunakan model pembelajaran bermain peran terhadap hasil belajar PPKn kelas V SD. Metode penelitian yang digunakan adalah metode penelitian kuantitatif dengan desain penelitian Pretest Posttest Control Design. Sampel yang digunakan adalah teknik sampling jenuh. Pada uji validitas dengan menggunakan Korelasi Point Biserial sebanyak 30 soal pilihan ganda dengan 20 soal valid dan 10 soal drop. Sedangkan pada uji reliabilitas menggunakan rumus KR-20 memperoleh rhitung $=0,85>\mathrm{r}_{\text {tabel }} 0,361$ maka data tersebut memiliki instrument yang reliabel. Selanjutnya data dianalisis uji persyaratan yaitu uji normalitas dengan menggunakan uji Liliefors diperoleh Lhitung pretest kelas kontrol $(0,081<0,161)$ pretest eksperimen $(0,130<0,161)$ dan untuk posttest kelas kontrol $(0,106<0,161)$ posttest eksperimen $(0,156<0,161)$ maka dapat disimpulkan bahwa data berdistribusi normal.

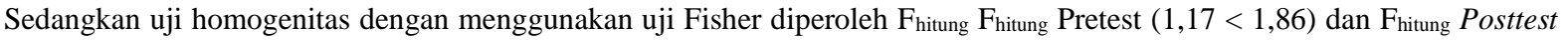
$(1,20<1,86)$ maka dapat disimpulkan bahwa uji homogenitas tersebut memiliki data varians kelompok berdistribusi homogen. Pada uji hipotesis digunakan uji-t diperoleh $\mathrm{T}_{\text {hitung }}=3,368$ dengan $\mathrm{dk}=58$, sedangkan $\mathrm{T}_{\text {tabel }}$ pada taraf signifikansi $(\alpha)=0,05$ dengan $\mathrm{dk}=58$ ialah sebesar 1,672. Berdasarkan hasil perhitungan tersebut diperoleh bahwa $\mathrm{T}_{\text {hitung }}>$ $\mathrm{T}_{\text {tabel }}(3,368>1,672)$ maka artinya adalah $\mathrm{H}_{0}$ (hipotesis nol) ditolak dan $\mathrm{H}_{1}$ (hipotesis kerja) diterima. Hal ini dapat disimpulkan dan dinyatakan bahwa adanya pengaruh positif yang signifikan pada penggunaan model role playing terhadap hasil belajar siswa kelas V Sekolah Dasar.
\end{abstract}

Kata kunci: Bermain Peran, PPKn, Hasil Belajar

\section{Abstract}

This study aims to analyze the effect of learning outcomes using the role-playing learning model on learning outcomes for fifth grade elementary school students. The research method used is a quantitative research method with a research design of Pretest Posttest Control Design. The sample used is a saturated sampling technique. In the validity test using the Biserial Point Correlation, there are 30 multiple choice questions with 20 valid questions and 10 drop questions. While the reliability test using the $\mathrm{KR}-20$ formula obtained $r$ rount $=0.85>$ rtable 0.361 , then the data has a reliable instrument.Furthermore, the data were analyzed by the requirements test, namely the normality test using the Liliefors test, obtained pretest for the control class $(0.081<0.161)$ was the experimental pretest $(0.130<0.161)$ and for the posttest control class $(0.106<0.161)$ the experimental posttest $(0.156<0.161)$ it can be concluded that the data is normally distributed. While the homogeneity pretest Fcount $(1.17<1.86)$ and Posttest Fcount $(1.20<1.86)$, it can be concluded that the homogeneity test has group variance data with homogeneous distribution.In the hypothesis test, the t-test was used to obtain Tcount $=3.368$ with $d k=58$, while Ttable at the significance level $(\alpha)=0.05$ with $d k=58$ was 1.672 . Based on the results of these calculations, it is found that Tcount > Ttable $(3.368>1.672)$ then it means that HO is rejected and HI is accepted. It can be concluded and stated that there is a significant positive effect on the use of role-playing models on the learning outcomes of fifth grade student of elementary school.

Keywords: Role-Playing, Ppkn, Learning Outcomes

\section{INTRODUCTION}

Pendidikan Kewarganegaraan (PPKn) adalah mata pelajaran yang wajib dipelajari di Indonesia disemua jenjang pendidikan dari SD sampai Perguruan Tinggi untuk mengembangkan kemampuan, membentuk harkat dan martabat bangsa, serta mencerdaskan kehidupan bangsa (Khoeriyah \& Mawardi, 2018; Sutiyono, 2018). Namun faktanya PPKn tidak mampu mewujudkan warga negara yang sesuai oleh Pancasila dan UUD 1945, hal ini dapat dibuktikan oleh sikap siswa yang kurang menghargai guru, adanya bullying dan sebagainya dimana semua itu berlawanan dengan nilai - nilai yang terdapat dalam Pancasila dan UUD 1945 (Asriani et al., 2017; Mariana, 2019). Hal ini dapat dibuktikan oleh sikap

$\begin{array}{ll}\text { History: } & \\ \text { Received } & \text { :August 07, } 2021 \\ \text { Revised } & \text { : August 10, } 2021 \\ \text { Accepted } & \text { : October 09, } 2021 \\ \text { Published } & \text { : October 25, } 2021\end{array}$


siswa yang kurang menghargai guru, adanya bullying dan sebagainya dimana semua itu berlawanan dengan nilai - nilai yang terdapat dalam Pancasila dan UUD 1945 (Adibah, 2016; Faisal \& Sulkipani, 2016). Pembelajaran merupakan proses, yaitu proses mengorganisasi, mengatur lingkungan yang ada di sekitar siswa sehingga mampu mendorong dan menumbuhkan siswa melakukan proses belajar. pembelajaran juga dikatakan sebagai proses memberikan bantuan atau bimbingan kepada siswa dalam melakukan proses belajar (Haryanti, 2016; Nugroho et al., 2017).

Agar tercapainya tujuan pembelajaran guru harus memilih suatu model belajar yang sesuai dengan tujuan yang telah ditentukan. Pemilihan model sangat dipengaruhi oleh sifat dari materi yang akan disampaikan, tingkat kemampuan siswa dan tujuan yang akan dicapai (Kumape, 2015; Pitriah \& Taufik, 2016). Dengan demikian pemilihan model pembelajaran akan mempengaruhi hasil belajar siswa. Setelah melakukan observasi di SDN Pademangan Barat 11 Pagi fakta yang terjadi dilapangan ialah ditemukan adanya suatu permasalahan tentang hasil belajar siswa yaitu rendahnya hasil belajar siswa pada mata pelajaran PPKn. Hal ini diakibatkan siswa tidak dilibatkan langsung dalam pembelajaran membuat siswa menjadi tidak termotivasi dalam belajar. Sikap kurang aktif siswa dalam pembelajaran ditunjukkan dengan sedikitnya siswa yang bertanya antara siswa dengan siswa maupun siswa dengan guru dan sedikitnya bertukar pendapat antar siswa. Siswa yang tidak dilibatkan langsung dalam pembelajaran akan membuat siswa menjadi jenuh atau bosan sehingga siswa sulit menerima materi yang disampaikan dan kurang memahami materi yang sedang disampaikan. Keterlibatan siswa secara aktif merupakan pondasi utama dalam pembelajaran yang sedang berlangsung dan merupakan hal yang sangat penting agar proses belajar menjadi efektif dan efesien.

Berdasarkan permasalahan tersebut maka dibutuhkan solusi untuk mengatasinya, salah satu solusi yang dapat di gunakan untuk mengatasi permasalahan tersebut adalah menggunakan model bermain peran. Untuk anak kelas $\mathrm{V}$ model bermain peran dapat meningkatkan keaktifan siswa dan melibatkan siswa dalam kegiatan belajar mengajar, sehingga dapat meningkatkan minat siswa dalam mengikuti pembelajaran (Lahir et al., 2017; Octavia, 2020). Bermain Peran adalah salah satu model pembelajaran secara sosial, yaitu suatu model pembelajaran yang menugaskan siswa untuk memerankan suatu tokoh dalam peristiwa atau materi yang diungkapkan dalam bentuk cerita (Kasanah et al., 2019; Widnyana \& Sujana, 2017). Menerapkan model bermain peran siswa dapat mengeksplorasi hubungan, sikap, nilai, perasaan dan berbagai strategi dalam memecahkan masalah antar manusia dengan cara berdikusi dan memperagakan (Dewi, 2017; Novita, 2019). Faktanya penggunaan model ini jarang sekali diterapkan oleh guru di dalam kelas, guru lebih sering menerapkan model pembelajaran yang simple dan mudah dalam mengajar dan kurang memperdulikan pemahaman yang didapat oleh siswa, sehingga hal ini membuat kondisi yang terjadi di dalam kelas tidak sesuai yang diharapkan siswa. Pengetahuan yang tergantung dari bagaimana langkah dalam penyampaian yang dilakukan berhasil atau tidak tergantung dengan hasil tes yang dilakukan, karena guru hanya sebagai fasilitator atau mediator dalam pelengkap proses pembelajaran sedangkan siswa menjadi penentu berhasil atau tidaknya penelitian yang dilakukan (Sutianah, 2020; Utama, 2017). Belajar merupakan seluruh rangkaian aktivitas atau kegiatan dilakukan secara sadar oleh manusia yang mengakibatkan perubahan yaitu berupa penambahan kemahiran atau pengetahuan berdasarkan alat pengalaman dan indera (Nai, 2017; Puspitasari, 2018). Belajar suatu kata yang cukup diketahui oleh semua lapisan masyarakat. Untuk para mahasiswa maupun pelajar kata belajar ialah kata yang tidak asing didengar ataupun diketahui. Belajar sudah bagian yang tidak bisa dipisahkan dari semua aktivitas dalam menuntut ilmu di sekolah. Aktivitas belajar dilakukan setiap waktu sesuai dengan keinginan. Belajar adalah suatu proses kompleks yang terjadi pada semua orang dan berlangsung seumur hidup, sejak bayi hingga keliang lahat. Salah satu pertanda seseorang 
sudah belajar adalah adanya perubahan tingkah laku dalam dirinya. Perubahan tingkah laku tersebut menyangkut baik perubahan yang bersifat pengetahuan (kognitif) dan keterampilan (psikomotor) maupun yang menyangkut nilai dan sikap (afektif) (Nisa, 2017; Widyanti et al., 2019).

Penelitian terdahulu yang diawali pada kenyataan bahwa proses pembelajaran bersifat monoton siswa kurang berkembang dengan baik terhadap aspek kognitif, afektif dan psikomotorik sehingga hasil belajar dari mata pelajaran PPKn belum maksimal. Peneliti menerapkan model bermain peran dalam mata pelajaran PPkn. dalam penerapan tersebut didapatkan hasil bahwa pembelajaran PPKn dengan menggunakan model bermain peran mampu meningkatkan hasil belajar siswa kelas II SDN 003 Bangkinang Kota, hal tersebut dapat dibuktikan dari kenaikan nilai rata - rata yang diperoleh selama penelitian dilaksanakan (Ananda, 2018). Tujuan dari penelitian ini ialah untuk mengetahui adanya Pengaruh Model Bermain Peran terhadap Hasil Belajar PPKn Siswa Kelas V SDN Pademangan Barat 11 Pagi. Tujuan yang ingin dicapai dalam penelitian ini ialah untuk: 1) memperoleh data hasil belajar siswa dengan menggunakan model bermain peran. 2) mengetahui ada atau tidaknya pengaruh hasil belajar siswa dengan menggunakan model bermain peran pada materi Menghargai Keputusan Bersama.

\section{MATERIALS AND METHODS}

Rancangan penelitian ini menggunakan jenis penelitian kuantitatif dengan pendekatan Quasi Experiment (Mustafa et al., 2020) dengan menggunakan tipe pre-test posttest control design (Sugiyono, 2014). Populasi dalam penelitian ini yaitu keseluruhan siswa kelas V SDN Pademangan Barat 11 Pagi Jakarta Utara yang berjumlah 60 siswa. Sampel yang digunakan dalam penelitian ini menggunakan dua kelas yaitu kelas V-A dan V-B yang masing-masing berjumlah 30 siswa. Teknik yang digunakan dalam pengambilan sampel penelitian ini ialah nonprobability dengan teknik sampel sampling jenuh yang disesuaikan dengan penelitian. Metode pengumpulan data yang digunakan diantaranya: pretest, berisi 20 soal pilihan ganda guna untuk mengetahui kemampuan siswa sebelum diberikan perlakuan. posttest, berisi 20 soal pilihan ganda guna untuk mengetahui hasil belajar siswa setelah diberikan perlakuan. Adapun kisi-kisi soal yang digunakan dalam penelitian ini disajikan pada Tabel 1.

\section{Tabel 1. Instrumen Soal}

\begin{tabular}{ll}
\hline Kompetensi Dasar & \multicolumn{1}{c}{ Indikator Soal } \\
\hline $4.1 \quad$ Mengenal & Disajikan dalam bentuk soal pilihan ganda siswa dapat menunjukkan \\
bentuk-bentuk & pemimpin musyawarah dalam kelas \\
keputusan & Disajikan dalam bentuk soal pilihan ganda, siswa dapat memberikan \\
bersama & contoh keputusan bersama \\
& Disajikan dalam bentuk soal pilihan ganda, siswa dapat \\
& menunjukkan sikap yang tidak boleh dalam pengambilan keputusan \\
& Disajikan dalam bentuk soal pilihan ganda, siswa dapat \\
& mengidentifikasi sikap yang baik dalam musyawarah \\
& Disajikan dalam bentuk soal pilihan ganda, siswa dapat \\
& menyebutkan cara pemilihan ketua kelas \\
\hline
\end{tabular}

Sebelum digunakan untuk penelitian soal yang digunakan terlebih dahulu diujikan di sekolah yang berbeda namun di tingkatan yang sama agar mengetahui seberapa layak dan valid soal tersebut untuk penelitian. Validitas merupakan suatu ukuran yang membuktikan 
tingkat kevalidan atau kesahihan suatu instrument. Suatu Instrument dikatakan valid jika mampu mengukur apa yang hendak diinginkan atau diukur. Uji validitas dilakukan dengan menggunakan rumus korelasi biserial. Setelah uji validitas, langkah selanjutnya adalah melakukan pengukuran reliabilitas. Reliabilitas instrument dilakukan dengan rumus KR-20. Metode analisis data yang digunakan adalah analisis deskriptif (mean, median, dan modus), uji normalitas, uji homogenitas. Pengujian hipotesis dilakukan melalui Uji-t dengan ketentuan data yang terkumpul terdistribusi normal dan data bersifat homogen dengan berbantuan program Microsoft Excel.

\section{RESULTS AND DISCUSSION}

\section{Result}

Penelitian yang dilakukan di SDN Pademangan Barat 11 Pagi Jl. Budi Mulia RT.009/010, Kel.Pademangan Barat Kec.Pademangan Kode Pos : 14420 Jakarta Utara . yaitu membahas tentang apakah terdapat pengaruh atau tidak model bermain peran terhadap hasil belajar PPKn siswa kelas V SDN Pademangan Barat 11 Pagi. Penggunaan data untuk analisis penelitian adalah hasil pretest dan posttest kelas eksperimen dan kontrol. Pada kelas eksperimen siswa diberikan pembelajaran menggunakan model bermain peran dengan materi menghargai keputusan bersama. Sedangkan untuk kelas kontrol pembelajaran dilakukan dengan model konvensional. Tes diberikan pada awal pembelajaran untuk pretest dengan jumlah 20 soal pilihan ganda, sedangkan untuk posttest diberikan pada akhir pembelajaran dengan jumlah 20 soal pilihan ganda. Kemudian hasil pretest dan posttes dianalisis secara deskriptif menggunakan rumus mean, median dan modus dan di dapatkan hasil sebagai ratarata pretest 72 dan posttest dari kelas eksperimen 86,1 sedangkan rata - rata pretest 72,3 dan posttest kelas control 77,96. Rata-rata untuk pretest kelas kontrol lebih tinggi disbanding kelas eksperimen sedangkan untuk posttest kelas eksperimen lebih tinggi dari kelas control. dengan nilai tengah pretest dan posttest dari kelas eksperimen sebesar 72 dan 88,2 kelas kontrol sebesar 72,5 dan 78,5. Nilai maksimum yang di dapat dari kelas eksperimen adalah 100 sedangkan kelas kontrol 100 lalu nilai minimum kelas eksperimen untuk pretest 50 dan posttest 60 sedangkan untuk kelas kontrol pretest 50 dan posttest 55 .

Setelah itu dilakukan uji homogenitas dan uji normalitas u. Uji homogenitas diperoleh melalui uji Fisher sedangkan uji normalitas menggunakanUji Liliefors. Hasil uji normalitas yang diperoleh pada pretest kelas eksperimen sebesar 0,130 dan kelas kontrol 0,081 sedangkan untuk posttest kelas eksperimen diperoleh $\mathrm{L}_{\text {hitung }}$ sebesar 0,156 dan kelas kontrol sebesar 0,106. Jadi, dapat dikatakan bahwa $\mathrm{L}_{\text {hitung }}<\mathrm{L}_{\text {tabel }}$ oleh karena itu, $\mathrm{H}_{0}$ yang menyatakan sampel berdistribusi normal dapat diterima. Dapat disimpulkan bahwa kelas eksperimen dan kelas kontrol adalah data yang berdistribusi normal sehingga memenuhi syarat untuk melakukan uji hipotesis. Uji persyaratan lainnya ialah uji homogenitas. Setelah dilakukan uji normalitas selanjutnya adalah uji homogenitas, Hasil uji homogenitas yang diperoleh pada pretest kelas eksperimen dan kelas control sebesar 1,17 sedangkan untuk posttest sebesar 1,20. Berdasarkan hasil perhitungan uji homogenitas, diperoleh $F_{\text {hitung }}$ pretest yaitu 1,17 , sedangkan $F_{\text {tabel }}$ pada taraf signifikansi $(\alpha)=0,05$ yaitu sebesar 1,86 . Sedangkan

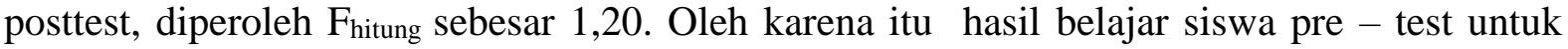
$F_{\text {hitung }}<F_{\text {tabel }}(1,17<1,86)$ dan hasil belajar post - test untuk $F_{\text {hitung }}<F_{\text {tabel }}(1,20<1,86)$. Maka dapat disimpulkan bahwa kedua kelompok tersebut bersifat homogen. Adapun hasil pengujian hipotesis disajikan pada Tabel 2. 
Tabel 2. Hasil Uji Hipotesis

\begin{tabular}{|c|c|c|}
\hline Kelompok Data & Kelas Eksperimen & Kelas Kontrol \\
\hline Varians & 90,91 & 109,65 \\
\hline Banyak Data & 30 & 30 \\
\hline $\mathrm{A}$ & \multicolumn{2}{|c|}{0,05} \\
\hline Rata - Rata & 86,1 & 77,96 \\
\hline & \multicolumn{2}{|c|}{8,14} \\
\hline $\mathrm{dk}$ & \multicolumn{2}{|c|}{58} \\
\hline $\mathrm{T}_{\text {hitung }}$ & \multicolumn{2}{|c|}{3,368} \\
\hline $\mathrm{T}_{\text {tabel }}$ & \multicolumn{2}{|c|}{1,672} \\
\hline Kriteria Pengujian & \multicolumn{2}{|c|}{$3,368>1,672$} \\
\hline Status & \multicolumn{2}{|c|}{$\mathrm{H}_{0}$ ditolak $\mathrm{H}_{1}$ diterima } \\
\hline
\end{tabular}

Hasil dari uji-t diperoleh $t_{\text {hitung }}$ sebesar 3,368 dan memiliki nilai signifikan yaitu 1,672. Karena $\mathrm{T}_{\text {hitung }}>\mathrm{T}_{\text {tabel }}(3,368>1,672)$ maka artinya adalah $\mathrm{H}_{0}$ ditolak dan $\mathrm{H}_{1}$ diterima. Hal ini menunjukkan berarti bahwa rata - rata kelas eksperimen yang menggunakan model bermain peran lebih tinggi dibandingkan rata - rata kelas kontrol yang menggunakan metode tanya jawab. Disimpulkan bahwa terdapat pengaruh pada penggunaan model bermain peran terhadap hasil belajar siswa kelas V SDN Pademangan Barat 11 Pagi.

\section{Pembahasan}

Berdasarkan hasil perhitungan penelitian data pada statistik diperoleh bahwa skor rata - rata hasil belajar siswa kelas eksperimen setelah diberi perlakuan dengan model bermain peran mencapai hasil yang lebih besar dibandingkan dengan skor rata - rata hasil belajar siswa kelas kontrol yang tidak diberi perlakuan model bermain peran dan diberikan dengan metode tanya jawab. Selain rata-rata hasil belajar mengalami peningkatan, dari hasil perhitungan data yang diperoleh bahwa data kelas eksperimen dan kelas kontrol berdistribusi normal setelah diuji normalitas dengan menggunakan uji Liliefors. Dari kedua kelas tersebut juga mempunyai varians yang homogen dari perhitungan uji homogenitas dengan menggunakan uji Fisher. Selanjutnya, dari hasil pengujian hipotesis dengan menggunakan uji - $\mathrm{t}$ pada taraf signifikansi $(\alpha)=0,05$ diperoleh bahwa $T_{\text {hitung }}>T_{\text {tabel }}(3,368>1,672)$, hasil tersebut mempunyai arti bahwa $\mathrm{H}_{0}$ ditolak dan $\mathrm{H}_{1}$ diterima. Hasil pengujian tersebut juga membuktikan bahwa model bermain peran memiliki pengaruh terhadap hasil belajar siswa kelas V SDN Pademangan Barat 11 Pagi.

Berdasarkan hasil pengujian data penelitian yang telah dijelaskan sebelumnya, dapat dinyatakan bahwa hasil belajar siswa mengalami perubahan yang signifikan karena dipengaruhi oleh adanya penerapan model bermain peran dalam kegiatan belajar mengajar. Keberhasil model bermain peran dalam mempengaruhi hasil belajar siswa dikarenakan siswa terlibat secara aktif dalam pembelajaran yang sedang berlangsung. Model bermain peran melatih siswa untuk melakukan komunikasi antar siswa satu dengan yang lainnya (Prasetyo \& Santoso, 2018; Puspitasari, 2018). Bukan hanya melatih siswa dalam berkomunikasi saja. Model pembelajaran bermain peran juga dapat memberikan rasa percaya diri siswa (Utama, 2017; Yusuf et al., 2018). Siswa dapat mengemukakan pendapatnya mengenai peristiwa yang sedang terjadi dengan percaya diri. Melalui model bermain peran, maka kegiatan pembelajaran akan menyenangkan dan siswa menjadi semangat dalam belajar (Utama, 2017; Wibowo et al., 2019). Berbeda dengan pembelajaran yang menggunakan metode tanya jawab. Dengan menggunakan metode tanya jawab siswa kurang berkembang dengan maksimal dikarenakan pada saat pembelajaran guru lebih mendominasi dalam pembelajaran (Merera et al., 2019; Widyanti et al., 2019). 
Bermain Peran adalah salah satu model pembelajaran secara sosial, yaitu suatu model pembelajaran yang menugaskan siswa untuk memerankan suatu tokoh dalam peristiwa atau materi yang diungkapkan dalam bentuk cerita (Kasanah et al., 2019; Widnyana \& Sujana, 2017). Menerapkan model bermain peran siswa dapat mengeksplorasi hubungan, sikap, nilai, perasaan dan berbagai strategi dalam memecahkan masalah antar manusia dengan cara berdikusi dan memperagakan (Dewi, 2017; Novita, 2019). Faktanya penggunaan model ini jarang sekali diterapkan oleh guru di dalam kelas, guru lebih sering menerapkan model pembelajaran yang simple dan mudah dalam mengajar dan kurang memperdulikan pemahaman yang didapat oleh siswa, sehingga hal ini membuat kondisi yang terjadi di dalam kelas tidak sesuai yang diharapkan siswa. Pengetahuan yang tergantung dari bagaimana langkah dalam penyampaian yang dilakukan berhasil atau tidak tergantung dengan hasil tes yang dilakukan, karena guru hanya sebagai fasilitator atau mediator dalam pelengkap proses pembelajaran sedangkan siswa menjadi penentu berhasil atau tidaknya penelitian yang dilakukan (Sutianah, 2020; Utama, 2017). Belajar merupakan seluruh rangkaian aktivitas atau kegiatan dilakukan secara sadar oleh manusia yang mengakibatkan perubahan yaitu berupa penambahan kemahiran atau pengetahuan berdasarkan alat pengalaman dan indera (Nai, 2017; Puspitasari, 2018).

\section{CONCLUSION}

Berdasarkan pembahasan di atas dapat disimpulkan bahwa penggunaan model bermain peran saat kegiatan belajar mengajar berpengaruh terhadap hasil belajar siswa kelas V di SDN Pademangan Barat 11 Pagi. Hal ini dapat dibuktikan dari skor rata - rata siswa di kelas eksperimen lebih tinggi dibandingkan kelas kontrol.

\section{REFERENCES}

Adibah, I. Z. (2016). Pendidikan Multikultural sebagai Wahana Pembentukan Karakter. Madaniyah: Terciptanya Insan Akademis Berkualitas \& Berakhlak Mulia, 4(2). https://journal.stitpemalang.ac.id/index.php/madaniyah/article/view/42.

Ananda, R. (2018). Peningkatan Pembelajaran PKn dengan Penerapan Metode Role-Playing Siswa Kelas II SDN 003 Bangkinang Kota. Jurnal Basicedu, 2(1), 33-42. https://www.neliti.com/publications/278080/peningkatan-pembelajaran-pkn-denganpenerapan-metode-role-playing-siswa-kelas-ii.

Asriani, P., Sa'dijah, C., \& Akbar, S. (2017). Bahan Ajar Berbasis Pendidikan Karakter Untuk Siswa Kelas IV Sekolah Dasar. Jurnal Pendidikan: Teori, Penelitian, Dan Pengembangan, 2(11), 1456-1468.

Dewi, C. (2017). Peningkatan Keterampilan Berbicara Dalam Bermain Drama Melalui Model Pembelajaran Kooperatif Tipe Inside-Outside Circle. JINoP (Jurnal Inovasi Pembelajaran), 3(2), 567-575. https://doi.org/10.22219/jinop.v3i2.4575

Faisal, E. El, \& Sulkipani, S. (2016). Pengembangan bahan ajar berbasis muatan lokal pada mata kuliah Pendidikan Kewarganegaraan. Jurnal Civics: Media Kajian Kewarganegaraan, 13(2), 113-126. https://doi.org/10.21831/civics.v13i2.12721.

Haryanti, Y. D. (2016). Peningkatan Hasil Belajar Dengan Menggunakan Model Cooperative Learning Type Inside-Outside Circle. Jurnal Cakrawala Pendas, 2(2). https://doi.org/10.31949/jcp.v2i2.337.

Kasanah, S. A., Damayani, A. T., \& Rofian, R. (2019). Keefektifan Model Pembelajaran Role Playing Berbantuan Media Multiply Cards terhadap Hasil Belajar Siswa. Jurnal Ilmiah Sekolah Dasar, 3(4), 519-526. https://doi.org/10.23887/jisd.v3i4.22308.

Khoeriyah, N., \& Mawardi, M. (2018). Penerapan Desain Pembelajaran Tematik Integratif 
Alternatif Berbasis Kearifan Lokal untuk Meningkatkan Hasil dan Kebermaknaan Belajar. Mimbar Sekolah Dasar, 5(2), 63. https://doi.org/10.17509/mimbarsd.v5i2.11444.

Kumape, S. (2015). Pengaruh Penerapan Model Pembelajaran Kooperatif Tipe Two Stay Two Stray Terhadap Aktivitas dan Hasil Belajar Siswa Tentang IPA di Kelas VI SD Inpres Palupi. Jurnal Kreatif Todulako Online, 4(4). http://jurnal.untad.ac.id/jurnal/index.php/JKTO/article/view/6131.

Lahir, S., Ma'ruf, M. H., \& Tho'in, M. (2017). Peningkatan Prestasi Belajar Melalui Model Pembelajaran Yang Tepat Pada Sekolah Dasar Sampai Perguruan Tinggi. Jurnal Ilmiah Edunomika, 1(01), 1-8. https://doi.org/10.29040/jie.v1i01.194.

Mariana. (2019). Peningkatan Pembelajaran PPKN Materi Persiapan Kemerdekaan Indonesia Melalui Pendekatan Contextual Teaching And Learning (CTL) Pada Siswa Kelas VI SD Negeri Muka Blang. Jurnal Sains Riset, 9(1), 29-42. http://journal.unigha.ac.id/index.php/JSR/article/view/48.

Merera, R. E., Sumartini, S., \& Susilo, S. V. (2019). Penggunaan Model Sosiodrama Dalam Keterampilan Berbicara Siswa Pada Pembelajaran Bahasa Indonesia. Prosiding Seminar Nasional Pendidikan, 1, 397-403. https://prosiding.unma.ac.id/index.php/semnasfkip/article/view/57.

Mustafa, P. S., Gusdiyanto, H., Victoria, A., Masgumelar, N. K., Lestariningsih, N. D., Maslacha, H., Ardiyanto, D., Hutama, H. A., Boru, M. J., \& Fachrozi, I. (2020). Metodologi Penelitian Kuantitatif, Kualitatif, dan Penelitian Tindakan Kelas dalam Pendidikan Olahraga. Fakultas Ilmu Keolahragaan Universitas Negeri Malang.

Nai, F. A. (2017). Teori Belajar dan Pembelajaran Implementasinya dalam Pembelajaran Bahasa Indonesia di SMP, SMA, dan SMK. Deepublish.

Nisa, A. (2017). Pengaruh Perhatian Orang Tua dan Minat Belajar Siswa Terhadap Prestasi Belajar Ilmu Pengetahuan Sosial. Faktor: Jurnal Ilmiah Kependidikan, 2(1), 1-9. https://journal.lppmunindra.ac.id/index.php/Faktor/article/view/370.

Novita, K. (2019). Strategi Membangun Keterampilan Komunikasi Dan Kepercayaan Diri Dalam Pembelajaran Public Speaking Melalui Metode Presentasi Dan Role Playing Miss Universe Asean (Studi Kasus Materi Interaksi Keruangan dalam Kehidupan di Negara-negara ASEAN Kelas VIII SMP. Jurnal Pendidikan Dompet Dhuafa, 9(02), 23-30. http://jurnal.makmalpendidikan.net/index.php/JPD/article/view/172.

Nugroho, J. S., Mahfud, H., \& Karsono. (2017). Penerapan Model Means Ends Analysis (Mea) Untuk Meningkatkan Kemampuan Menyelesaikan Soal Cerita Mata Pelajaran Matematika Pada Siswa Sekolah Dasar. Jurnal Didaktika Dwija Indria (SOLO), 5(4).

Octavia, S. A. (2020). Model-Model Pembelajaran. Deepublish.

Pitriah, S., \& Taufik, M. (2016). Pengaruh Model Pembelajaran Berbasis Masalah Berbantuan Alat Peraga Tiga Dimensi terhadap Hasil Belajar Fisika Peserta Didik Tahun Pelajaran 2017/2018. Jurnal Pendidikan Fisika dan Teknologi. Jurnal Pendidikan Fisika Dan Teknologi, 4(2), 283-290. http://jurnalfkip.unram.ac.id/index.php/JPFT/article/view/566.

Prasetyo, A., \& Santoso, D. A. A. (2018). Pengaruh Teknik Bermain Peran terhadap Keterampilan Berbicara. DEIKSIS, 10(02), 85-91. https://journal.lppmunindra.ac.id/index.php/Deiksis/article/view/2375.

Puspitasari. (2018). Metode Pembelajaran Bermain Peran Pada Pembelajaran Bahasa Indonesia. Jurnal Cakrawala Pendas, I(1), 55-64. https://www.researchgate.net/deref/http\%3A\%2F\%2Fdx.doi.org\%2F10.31949\%2Fjcp .$v 111.347$.

Sugiyono. (2014). Metode Penelitian Pendidikan Pendekatan Kuantitatif, Kualitatif, dan $R \& D$. Alfabeta. 
Sutianah, C. (2020). Pengembangan Karakter Kebangsaan Dan Karakter Wirausaha Melalui Implementasi Model Pembelajaran Teaching Factory 6 Langkah (TF-6M). Penerbit Qiara Media.

Sutiyono, S. (2018). Reformulasi Pendidikan Pancasila Dan Kewarganegaraan Untuk Menguatkan Nasionalisme Warga Negara Muda Di Wilayah Perbatasan. Citizenship Jurnal Pancasila Dan Kewarganegaraan, 6(1), 1. https://doi.org/10.25273/citizenship.v6i1.1824.

Utama, W. (2017). Pengaruh Metode Bermain Peran dan Konsep Diri terhadap Kemampuan Berbicara Bahasa Inggris Siswa SMK Swasta di Jakarta Selatan (Eksperimen pada Siswa Kelas X SMK Swasta di Jakarta Selatan). Deiksis, 9(02), 247. https://doi.org/10.30998/deiksis.v9i02.1512.

Wibowo, N. A. K., Susanto, B., \& Maulana, M. A. (2019). Pengaruh Layanan Bimbingan Kelompok Teknik Role Playing Terhadap Interaksi Sosial Pada Siswa. Advice: Jurnal Bimbingan Dan Konseling, $\quad 1(1), \quad 46-54$. http://journal.univetbantara.ac.id/index.php/Advice/article/view/289.

Widnyana, I. G., \& Sujana, I. W. (2017). Pengaruh Model Pembelajaran Role Playing Berbasis Tri Hita Karana Terhadap Kompetensi Pengetahuan Ips Kecamatan Denpasar Timur Tahun Pelajaran 2016 / 2017. MIMBAR PGSD Undiksha, 5(2). https://doi.org/10.23887/jjpgsd.v5i2.11995.

Widyanti, A., Dharsana, I. K., \& Suarn, N. K. (2019). Efektivitas Konseling Kognitif Sosial Teknik Bermain Peran untuk Meningkatkan Self Afiliasi. Jurnal Ilmiah Bimbingan Konseling Undiksha, 10(1), 32-40. https://doi.org/10.23887/jibk.v10i2.23284.

Yusuf, M., Tarjiah, I., \& Satibi, O. (2018). Penerapan Metode Simulasi untuk Meningkatkan Keterampilan Sosial Siswa dalam Pembelajaran IPS. Jurnal Tunas Bangsa, 5(2), 124132. https://ejournal.bbg.ac.id/tunasbangsa/article/view/660. 